\title{
Avaliação agroeconômica das culturas da beterraba e coentro em função da época de estabelecimento do consórcio ${ }^{1}$
}

\author{
Agroeconomic evaluation of sugar beet and coriander depending on the time of \\ intercropping establishment
}

\author{
Leilson Costa Grangeiro ${ }^{2 *}$, Allysson Pereira Santos ${ }^{3}$, Francisco Claúdio Lopes Freitas ${ }^{4}$, Livia Maciel Costa \\ Simão ${ }^{5}$ Francisco Bezerra Neto
}

\begin{abstract}
Resumo - A consorciação de culturas é uma prática de cultivo usada na produção de hortaliças, e que influencia sobremaneira a produtividade dessas culturas, além de gerar vários benefícios agroeconômicos. O objetivo do presente trabalho foi avaliar os rendimentos de beterraba (Beta vulgarias L.) e coentro (Coriandrum sativum L.) em função da época de estabelecimento do consórcio entre essas culturas. $\mathrm{O}$ trabalho foi conduzido na Universidade Federal Rural do Semiárido, Mossoró-RN, durante o período de julho a setembro de 2006. O delineamento experimental utilizado foi em blocos completos aleatorizados, com sete tratamentos e quatro repetições. Os tratamentos analisados corresponderam aos cultivos consorciados de beterraba e coentro plantados aos $0 ; 7$ e 14 dias após a semeadura da beterraba (Tratamentos 1; 2 e 3), cultivo solteiro da beterraba (Tratamento 4) e, os cultivos solteiros do coentro plantados nas mesmas épocas de estabelecimento dos consórcios (Tratamentos 5; 6 e 7). O cultivo consorciado de beterraba com coentro é agroeconomicamente viável. Ele deve ser estabelecido com o plantio do coentro realizado simultaneamente ou aos sete dias após a semeadura da beterraba.
\end{abstract}

Palavras-chave - Beterraba. Coentro. Cultivos agrícolas.

\begin{abstract}
Intercropping is a cropping practice widely used in the production of vegetables, and that greatly influences the productivity of these crops, and generates multiple agroeconomic benefits. The aim of this study was to evaluate the yield of sugar beet (Beta vulgaris L.) and coriander (Coriandrum sativum L.) depending on the time of intercropping establishment between these crops. The work was conducted at the Universidade Federal Rural do Semi-arid, Mossoró, RN, during the period from July 2006 to September 2006. The experimental design was of randomized complete blocks with seven treatments and four replications. The treatments consisted of the intercropping of coriander and beet planted at 0,7 and 14 days after sowing of beet (Treatments 1; 2 and 3), sole crop of beet (Treatment 4) and the sole crops of coriander planted at the same times of intercropping establishment (Treatments 5; 6 and 7). The intercropping of sugar beet with coriander is agronomically feasible, and that this should be planted simultaneously or with the planting of coriander at seven days after sowing of beets, when were also obtained higher values of land equivalent ratio.
\end{abstract}

Key words - Beta vulgaris. Coriandrum sativum. Crop association.

\footnotetext{
* Autor para correspondência

${ }^{1}$ Recebido para publicação em 21/07/2009; aprovado em 14/12/2010

Parte do trabalho de conclusão do segundo autor no curso de graduação em Agronomia/UFERSA

2Departamento de Ciências Vegetais, Universidade Federal Rural do Semiárido, BR 110, KM 47, 59625-900, Mossoró-RN, Brasil, leilson@ufersa.edu.br ${ }^{3}$ Programa de Pós-Graduação em Ciências do solo/UFERSA, BR 110, KM 47, 59625-900, Mossoró-RN, Brasil, allysoneng@hotmail.com ${ }^{4}$ Departamento de Ciências Vegetais/UFERSA, BR 110, KM 47, 59625-900, Mossoró-RN, Brasil, franciscoclaudio@ufersa.edu.br ${ }^{5}$ Graduada em Agronomia pela Universidade Federal Rural do Semiárido, BR 110, KM 47, 59625-900, Mossoró-RN, Brasil, lívia_mac@hotmail.com.

${ }^{6}$ Departamento de Ciências Vegetais, UFERSA, BR 110, KM 47, 59625-900, Mossoró-RN, Brasil, bezerra@ufersa.edu.br
} 


\section{Introdução}

No Rio Grande do Norte, a produção de algumas hortaliças é restrita e pouco expressiva, como a beterraba, não produzindo o suficiente para atender a sua demanda interna, havendo a necessidade de importação de outros estados. Por outro lado, o coentro é uma das hortaliças mais populares da culinária nordestina, cujas folhas são utilizadas na composição e decoração de diversos pratos regionais. Embora, seja considerada uma "cultura de fundo de quintal”, grande número de produtores está envolvido com a sua exploração durante todo o ano, tornado-a cultura de grande importância social e econômica. É tradicionalmente cultivado por pequenos produtores, em hortas domésticas, escolares e comunitárias, em cultivo solteiro ou consorciado com outras hortaliças, principalmente cebolinha e alface.

O consórcio de culturas é prática tradicional de produção de alimentos e biomassa vegetal e entre as vantagens proporcionadas pela sua adoção destaca-se o aproveitamento mais eficaz dos recursos naturais (HUMPHRIES et al., 2004). No caso das hortaliças, pesquisas têm sido realizadas, buscando obter um maior conhecimento sobre os aspectos desse sistema no que se refere às espécies e cultivares mais adequadas, arranjo espacial e densidade de plantio, épocas de estabelecimento do consórcio, entre outros (SALVADOR et al., 2004; SANTANA et al., 2009; TEÓFILO et al., 2009; TOLENTINO JÚNIOR et al., 2002; VIEIRA et al., 2003).

Na região nordeste, os estudos ainda são incipientes e apresentam amplas possibilidades. Entretanto, já ficou comprovada a eficiência agroeconômica de sistemas de cultivo consorciados entre as culturas da cenoura e alface (BEZERRA NETO et al., 2003; BEZERRA NETO et al., 2005; NEGREIROS et al., 2002; OLIVEIRA et al., 2004; PIMENTEL et al., 2009), alface e coentro (FREITAS et al., 2004; OLIVEIRA et al., 2005), beterraba e rúcula (GRANGEIRO et al., 2007).

$\mathrm{Na}$ literatura consultada, não foram encontrados relatos de trabalhos científicos sobre a consorciação de beterraba e coentro. As mesmas são divergentes quanto ao ciclo, ao porte, à arquitetura, à exigência em água, luz e aos nutrientes, entre outros fatores em sistemas consorciados (GLIESSMAN, 2001). Pode também resultar em vantagens agronômicas e econômicas aos produtores de hortaliças da região, através do incremento da produção por unidade de área plantada, otimização dos recursos de produção, aproveitamento de forma mais adequada dos insumos disponíveis, além da diversificação dos produtos colhidos pelo produtor.
Nesse contexto, o objetivo do trabalho foi avaliar agroeconomicamente as culturas da beterraba e coentro em função da época de estabelecimento do consórcio.

\section{Material e métodos}

O experimento foi realizado na horta do Departamento de Ciências Vegetais da Universidade Federal Rural do Semiárido em Mossoró, no período de julho a setembro de 2006, em solo classificado como Argissolo Vermelhoamarelo. O clima do município de Mossoró, cujo distrito sede está situado a $5^{\circ} 11^{\prime}$ de latitude Sul e $37^{\circ} 20^{\prime}$ de longitude Oeste, e apresenta altitude média de $18 \mathrm{~m}$, é segundo a classificação de Köppen, do tipo BSwh', isto é, seco e muito quente, com duas estações climáticas (uma seca, que mais comumente ocorre de junho a janeiro, e outra chuvosa, de fevereiro a maio), temperatura média anual de $27,4{ }^{\circ} \mathrm{C}$, precipitação pluviométrica anual (irregular) média de $673 \mathrm{~mm}$ e umidade relativa do ar média de 68,9\% (CARMO FILHO et al., 1991). Da área experimental foram retiradas amostras de solo, cuja análise química, teve os seguintes resultados: $\mathrm{pH}$ (água) 8,2; $110,4 \mathrm{mg} \mathrm{dm}^{-3}$ de P; 0,33 $\mathrm{cmol}_{\mathrm{c}} \mathrm{dm}^{-3}$ de K; 5,3 $\mathrm{cmol}_{\mathrm{c}} \mathrm{dm}^{-3} \mathrm{de}$ $\mathrm{Ca} ; 0,14 \mathrm{cmol}_{\mathrm{c}} \mathrm{dm}^{-3}$ de Na e 3,1 $\mathrm{cmol}_{\mathrm{c}} \mathrm{dm}^{-3}$ de $\mathrm{Mg}$.

O delineamento experimental utilizado foi em blocos completos aleatorizados, com sete tratamentos e quatro repetições. Os tratamentos analisados corresponderam aos cultivos consorciados de beterraba e coentro plantados aos 0; 7 e 14 dias após a semeadura da beterraba (Tratamentos 1; 2 e 3), cultivo solteiro da beterraba (Tratamento 4) e, os cultivos solteiros do coentro plantados nas mesmas épocas de estabelecimento dos consórcios (Tratamentos 5; 6 e 7). Para as características do coentro, o procedimento de análise dos dados foi realizado no modelo de blocos completos aleatorizados, em esquema fatorial 2 (sistemas de cultivos: consórcio e cultivo solteiro) x 3 (épocas de semeadura do coentro: 0; 7 e 14 DAS).

Por outro lado, para as características da beterraba, o procedimento de análise dos dados foi realizado no modelo de blocos completos aleatorizados com quatro tratamentos, os quais corresponderam à beterraba em cultivo solteiro e três consórcios com o coentro plantado aos $0 ; 7$ e 14 dias após a semeadura da beterraba (DAS).

A unidade experimental teve área total de $1,20 \mathrm{~m}^{2}$, compreendendo quatro linhas de plantio de beterraba em consórcio e no cultivo solteiro plantado no espaçamento de $0,30 \times 0,10 \mathrm{~m}$. Para o coentro, tiveram-se quatro linhas em cultivo solteiro e três linhas em consórcio, no espaçamento de $0,30 \mathrm{~m}$ entrelinhas e $0,05 \mathrm{~m}$ entre plantas. A área útil da parcela foi de $0,50 \mathrm{~m}^{2}$, em ambos os sistemas. Nos 
consórcios, a semeadura do coentro foi realizada no sentido longitudinal do canteiro, nas entrelinhas da beterraba.

O preparo do solo constou de uma gradagem, seguida do levantamento dos canteiros. As adubações de plantio e de cobertura para ambas as culturas, foram realizadas com base na análise de solo e recomendação de Cavalcanti (1998), nos cultivos solteiros. Nos consórcios foi colocado 1,5 vezes a adubação recomendada para a cultura da beterraba. Como não existe na literatura recomendação oficial de adubação para cultivo consorciado e que nos trabalhos científicos tem-se adotado a adubação com base na cultura mais exigente, ou na cultura principal do consórcio (OLIVEIRA et al., 2004) ou ainda separadamente para cada hortaliça do consorcio (CECÍLIO FILHO; MAY, 2002; COSTA et al., 2007), e considerando que a adubação realizada no canteiro de plantio pode ser aproveitada por ambas as culturas, adotou-se no referido trabalho a utilização de 1,5 vezes a adubação realizada na beterraba (mais exigente em nutrientes em relação ao coentro). Para o cultivo solteiro do coentro foram realizadas duas adubações: a primeira aos 15 dias após a semeadura e a segunda 15 dias após a primeira. Para a cultura da beterraba (cultivo solteiro e consorciado) foram realizadas duas coberturas, aos $25 \mathrm{e}$ aos 45 dias após a semeadura.

A cultivar de beterraba Early Wonder foi semeada em covas utilizando quatro sementes e após 14 dias procedeu-se o desbaste, deixando-se uma planta por cova, tanto para o cultivo solteiro como para o consórcio. A cultivar de coentro Verdão, no cultivo solteiro foi semeada da mesma forma da beterraba, deixando-se no desbaste duas plantas por cova. No sistema de consórcio, a semeadura do coentro foi realizada de acordo com a época de estabelecimento do mesmo ( $0 ; 7$ e 14 dias após a semeadura da beterraba). A semeadura foi em covas entre as linhas da beterraba, utilizando quatro sementes por cova e após 14 dias procedeu-se o desbaste deixando-se duas plantas por cova.

O controle de plantas invasoras foi realizado com capinas manual e as irrigações diárias por microaspersão durante todo ciclo das culturas. A colheita da beterraba foi realizada aos 63 dias e do coentro aos 43 dias após a semeadura.

As características avaliadas foram: a) Coentro: Altura de plantas $(\mathrm{cm})$ - foram selecionadas ao acaso, 10 plantas da área útil de cada parcela e com auxilio de uma régua graduada efetuou-se a medida da altura das plantas. Massa fresca e seca da parte aérea $(\mathrm{g})$ - para a massa fresca foram utilizadas todas as 60 plantas colhidas da área útil da parcela, cortadas rentes ao chão e pesadas. Já para a massa seca da parte aérea foi retirada uma amostra de 20 plantas, colocadas em estufa de circulação forçada de ar e temperatura de $65{ }^{\circ} \mathrm{C}$, até atingir massa constante. Produtividade $\left(\mathrm{g} \mathrm{m}^{-2}\right)$ - A produtividade do coentro foi determinada com base na produção da área útil de cada parcela experimental. b) Beterraba: Altura de plantas (cm) - determinado da mesma forma que o coentro, sendo utilizadas cinco plantas da área útil da parcela. Massa seca da parte aérea (g) - Após a colheita, a planta foi separada em parte aérea e raiz, sendo que para a determinação da massa seca da parte aérea foi colocada em saco de papel a parte aérea de três plantas, levadas para estufa de circulação forçada de ar e temperatura de $65^{\circ} \mathrm{C}$, até atingir massa constante. Massa fresca e seca de raízes (g) - Após a separação da parte aérea e raiz, a massa fresca foi determinada dividindo a produção de raízes comercial e não comercial pelos respectivos números de raízes obtidas em cada parcela experimental. Para a quantificação da massa seca de raiz foram utilizadas todas as raízes comerciais da área útil da parcela, colocadas em estufa de circulação forçada de ar e temperatura de $65^{\circ} \mathrm{C}$, até atingir massa constante. Produtividade comercial e nãocomercial $\left(\mathrm{g} \mathrm{m}^{-2}\right)$ - para a produtividade comercial foram consideradas as raízes com diâmetro acima de $50 \mathrm{~mm}$, sem rachaduras e as raízes que não se enquadraram nesta categoria foram classificadas como não-comerciais. A estimativa da produtividade por hectare foi realizada para $70 \%$ da área plantada, em virtude de 30\% dela ser composta de área de trânsito e corredores. c) Índice de uso eficiente da terra (UET) foi utilizado para avaliar a eficiência do consórcio em relação ao cultivo solteiro segundo metodologia proposta por Willey (1979); d) Receita bruta $(\mathrm{RB})\left(\mathrm{R} \$ \mathrm{ha}^{-1}\right)$ : obtida através do produto da produção comercial das culturas em consórcio e cultivo solteiro $\left(\mathrm{kg} \mathrm{ha}^{-1}\right)$, pelo preço médio praticado na época de colheita nos principais supermercados de Mossoró-RN. A unidade de comercialização da beterraba adotada nas redes de supermercados é quilo do produto e do coentro, molho com aproximadamente $40 \mathrm{~g}$; e) Custo operacional (R\$ ha-1), considerou-se os desembolsos efetivos realizados pelo produtor durante o ciclo produtivo das culturas englobando despesas com mão-de-obra, operações de máquinas e insumos; f) Renda líquida (RL) $\left(\mathrm{R} \$ \mathrm{ha}^{-1}\right)$ : obtida pela diferença entre a receita bruta e o custo operacional $(\mathrm{CO})$, por ciclo.

Análises univariada de variância foram realizadas tanto nas características do coentro como nas características da beterraba de acordo com os procedimentos de análise de dados, descritos anteriormente para o delineamento em blocos completos aleatorizados. Estas análises foram realizadas através do software SAEG (RIBEIRO JÚNIOR, 2001). As pressuposições da normalidade, homocedasticidade e aditividade foram encontradas em todas as características avaliadas. O teste de Duncan ao nível de $5 \%$ de probabilidade foi realizado na comparação das médias entre os fatores ou tratamentos testados. 


\section{Resultados e discussão}

\section{Cultura do coentro}

Os resultados da comparação entre os sistemas de cultivos e entre as épocas de semeadura na altura de plantas, massa seca da parte aérea e produtividade de coentro encontram-se nas Tabelas 1 e 2 . Diferença significativa foi observada entre os sistemas de cultivos apenas na massa seca da parte aérea, com o cultivo consorciado superando o cultivo solteiro do coentro em 27,4 (TAB. 1). Este efeito benéfico do consórcio se deve à complementaridade entre as culturas, conferindo-as a condição de plantas companheiras. Esta condição é denominada por Ceretta (1986) de cooperação mútua, na qual se tem um efeito benéfico entre as espécies e uma utilização máxima dos recursos ambientais.

A variabilidade dos dados das características avaliadas expressa pelo CV está um pouco acima do padrão normal dessas variáveis quando as culturas estão em cultivo solteiro. Essa variação pode ser explicada pelas características distintas das culturas e pelas diferentes condições de uso do solo e clima do ambiente (radiação solar, umidade relativa do ar e temperatura do ar), durante a execução do experimento.

Diferenças significativas entre as épocas de semeadura do coentro foram observadas apenas na massa seca da parte aérea e na produtividade do coentro (TAB. 2). As semeaduras do coentro na mesma época da beterraba e aos sete dias após a semeadura promoveram maior produtividade de coentro e acúmulo de massa seca da parte aérea, embora este valor de massa seca aos sete dias não tenha diferido significativamente do de 14 dias (TAB. 2). Tal comportamento é devido às culturas serem divergentes quanto ao ciclo, porte, arquitetura, exigência em água, luz e nutrientes. Considerando que, a maior demanda de nutrientes pela cultura da beterraba acontece após os 40 dias (SOUZA et al., 2006), a semeadura do coentro mais tardia favoreceu a maior convivência das espécies consorciadas neste período, com prejuízo para a cultura do coentro.

Em consórcios realizados no município de Mossoró-RN, o número de molhos por planta e a produtividade de coentro foram semelhantes nos sistemas consorciados coentro $\mathrm{x}$ cenoura e coentro $\mathrm{x}$ alface, evidenciando baixo poder de competição da cenoura e alface sobre o coentro, quando o estabelecimento desta hortaliça no consórcio com as culturas da alface e cenoura ocorreu aos 25 e 42 dias, respectivamente (FREITAS et al., 2004).

\section{Cultura da beterraba}

Os resultados da comparação entre os sistemas de cultivos e entre as épocas de semeadura do coentro na altura de plantas, massa seca da parte aérea e produtividade de beterraba encontram-se nas Tabelas 3 e 4 . Não se observou diferença significativa entre os sistemas de cultivos e nem entre as épocas de semeadura do coentro nas variáveis altura de plantas, massa seca da parte aérea e produtividade da beterraba. Desta forma,

Tabela 1 - Alturas de plantas, massa seca da parte aérea e produtividade de coentro em função dos sistemas de cultivos

\begin{tabular}{lccc}
\hline \multicolumn{1}{c}{ Sistemas de cultivos } & Altura de plantas $(\mathrm{cm})$ & Massa seca parte aérea $\left(\mathrm{g} \mathrm{planta}^{-1}\right)$ & Produtividade $\left(\mathrm{kg} \mathrm{m}^{-2}\right)$ \\
\hline Cultivo solteiro & $22,11 \mathrm{~A}^{*}$ & $1,17 \mathrm{~B}$ & $1,05 \mathrm{~A}$ \\
Consorciado & $23,26 \mathrm{~A}$ & $1,61 \mathrm{~A}$ & $0,87 \mathrm{~A}$ \\
\hline \multicolumn{1}{c}{$\mathrm{CV}(\%)$} & 23,0 & 20,1 & 30,1 \\
\hline
\end{tabular}

*Médias seguidas de mesma letra na coluna, não diferem entre si ao nível de 5\% pelo teste de Duncan

Tabela 2 - Altura de plantas, massa seca da parte aérea e produtividade de coentro em função das épocas de semeadura do coentro em relação à beterraba

\begin{tabular}{cccc}
\hline Épocas de semeadura (dias) & Altura de plantas $(\mathrm{cm})$ & Massa seca parte aérea $\left(\mathrm{g} \mathrm{planta}^{-1}\right)$ & Produtividade $\left(\mathrm{kg} \mathrm{m}^{-2}\right)$ \\
\hline 0 & $25,75 \mathrm{~A}^{*}$ & $1,59 \mathrm{~A}$ & $0,94 \mathrm{~A}$ \\
7 & $21,23 \mathrm{~A}$ & $1,42 \mathrm{AB}$ & $0,70 \mathrm{~B}$ \\
14 & $21,09 \mathrm{~A}$ & $1,17 \mathrm{~B}$ & $0,52 \mathrm{~B}$ \\
\hline
\end{tabular}

*Médias seguidas de mesma letra na coluna, não diferem entre si ao nível de 5\% pelo teste de Duncan 
Tabela 3 - Altura de plantas (ALT), massa fresca de raiz (MFR), massa seca de raiz (MSR), massa seca da parte aérea (MSPA), produtividade comercial (PDC) e produtividade não comercial (PDNC) de beterraba em função dos sistemas de cultivo

\begin{tabular}{lcclccc}
\hline Sistemas de cultivo & ALT $(\mathrm{cm})$ & MFR $(\mathrm{g})$ & MSR $(\mathrm{g})$ & MSPA $(\mathrm{g})$ & PDC $\left(\mathrm{kg} \mathrm{m}^{-2}\right)$ & PDNC $\left(\mathrm{kg} \mathrm{m}^{-2}\right)$ \\
\hline Consórcio & $31,05 \mathrm{~A}$ & $107,35 \mathrm{~A}$ & $14,51 \mathrm{~A}$ & $11,47 \mathrm{~A}$ & $2,45 \mathrm{~A}$ & $0,46 \mathrm{~A}$ \\
Cultivo solteiro & $30,13 \mathrm{~A}$ & $102,09 \mathrm{~A}$ & $14,20 \mathrm{~A}$ & $12,87 \mathrm{~A}$ & $1,91 \mathrm{~A}$ & $0,48 \mathrm{~A}$ \\
\hline \multicolumn{1}{c}{$\mathrm{CV}(\%)$} & 10,86 & 9,69 & 11,17 & 12,45 & 29,36 & 21,81 \\
\hline
\end{tabular}

*Médias seguidas de mesma letra na coluna, não diferem entre si ao nível de $5 \%$ pelo teste de Duncan

Tabela 4 - Altura de plantas (ALT), massa fresca de raiz (MFR), massa seca de raiz (MSR), massa seca da parte aérea (MSPA), produtividade comercial (PDC) e produtividade não comercial (PDNC) de beterraba em função das épocas de semeadura do coentro em relação à beterraba

\begin{tabular}{ccccccc}
\hline Épocas de semeadura (dias) & ALT $(\mathrm{cm})$ & MFR $(\mathrm{g})$ & MSR $(\mathrm{g})$ & MSPA $(\mathrm{g})$ & PDC $\left(\mathrm{kg} \mathrm{m}^{-2}\right)$ & PDNC $\left(\mathrm{kg} \mathrm{m}^{-2}\right)$ \\
\hline 0 & $31,66 \mathrm{~A}$ & $106,54 \mathrm{~A}$ & $13,62 \mathrm{~A}$ & $10,44 \mathrm{~A}$ & $2,27 \mathrm{~A}$ & $0,42 \mathrm{~A}$ \\
7 & $30,55 \mathrm{~A}$ & $108,27 \mathrm{~A}$ & $14,25 \mathrm{~A}$ & $12,41 \mathrm{~A}$ & $2,61 \mathrm{~A}$ & $0,46 \mathrm{~A}$ \\
14 & $30,95 \mathrm{~A}$ & $107,24 \mathrm{~A}$ & $15,66 \mathrm{~A}$ & $11,56 \mathrm{~A}$ & $2,46 \mathrm{~A}$ & $0,49 \mathrm{~A}$ \\
\hline $\mathrm{CV}(\%)$ & 10,86 & 9,69 & 11,17 & 12,45 & 29,36 & 21,81 \\
\hline
\end{tabular}

*Médias seguidas de mesma letra na coluna, não diferem entre si ao nível de $5 \%$ pelo teste de Duncan

a semeadura do coentro até 14 dias após a semeadura da beterraba não comprometeu o desempenho desta última, ou seja, a consorciação entre as duas espécies não prejudicou a cultura principal. Em consórcio de beterraba e alface, Souza e Macedo (2007) também não constataram diferenças estatísticas significativas nas variáveis analisadas na beterraba entre o cultivo solteiro desta cultura e os tratamentos consorciados.

Nos consórcios, geralmente, se detecta alguma redução na produtividade das espécies associadas quando comparadas com as dos cultivos solteiros, o que evidencia a necessidade de estudos direcionados ao melhor entendimento dos mecanismos ecológicos específicos envolvidos nesse modo de cultivo (GLIESSMAN, 2001). Porém, considerando que o coentro não interferiu no desempenho da beterraba, independentemente da época de estabelecimento do consórcio, evidencia-se do ponto de vista agronômico, que essa forma de cultivo é vantajosa, permitindo que com a cultura intercalar de coentro, obtenha-se uma produção adicional para uma dada área, além de otimizar as práticas culturais como capinas, irrigações e adubações. Comportamento semelhante foi observado por Catelan et al. (2001) quando do consórcio de beterraba com rúcula, onde a rúcula não prejudicou o desempenho da cultura principal (beterraba).

Esse fato pode indicar que a competição exercida pelo coentro por recursos ambientais como água, luz e nutrientes não foi suficiente para comprometer o desempenho da cultura de beterraba, ou pelos menos, não houve coincidência nos períodos de altas demandas por esses recursos pelas culturas envolvidas no consórcio. Segundo Willey (1979) quando o período de maior demanda por recursos pelas culturas consorciadas não é coincidente, a competição entre as mesmas pode ser minimizada.

\section{Indicadores de eficiência agronômica e econômica}

Os indicadores agroeconômicos dos sistemas consorciados de beterraba e coentro em função das épocas de semeadura do coentro e do cultivo solteiro da beterraba encontram-se na Tabela 5. Maiores eficiências biológicas e econômicas foram observadas quando a beterraba foi semeada no mesmo dia coentro ou quando o coentro foi semeado 7 dias depois da beterraba, cujos os indicadores foram: índices de uso da terra de 2,26 e 2,28; rendas brutas de $\mathrm{R} \$ 33.754,32$ e $\mathrm{R} \$ 26.051,32$ e rendas líquidas de $\mathrm{R} \$ 28.988,32$ e $\mathrm{R} \$ 21.285,32$.

Os valores do índice de uso eficiente da terra (UET), independentemente, da época de estabelecimento do consórcio foram superiores à unidade, indicando que os sistemas consorciados aproveitaram melhor os recursos ambientais disponíveis em relação ao cultivo solteiro. As semeaduras do coentro realizadas na mesma época e aos sete dias após a beterraba proporcionaram os maiores aumentos nos valores de UET, isto significa que são necessários 126 e 
Tabela 5 - Índices de eficiência agronômica (UET) e econômica (CO, RB e RL) de sistemas consorciados de beterraba e coentro e de cultivo solteiro de beterraba

\begin{tabular}{lcccc}
\hline \multicolumn{1}{c}{ Sistemas de cultivo } & UET & CO $\left(\mathrm{R} \$ h^{-1}\right)$ & RB $\left(\mathrm{R} \$ h^{-1}\right)$ & $\mathrm{RL}_{\left(\mathrm{R} \$ \mathrm{ha}^{-1}\right)}$ \\
\hline Beterraba + coentro 0 das & 2,26 & $4.766,00$ & $33.754,32$ & $28.988,32$ \\
Beterraba + coentro 7 DAS & 2,28 & $4.766,00$ & $26.051,32$ & $21.285,32$ \\
Beterraba + coentro 14 DAS & 2,03 & $4.867,00$ & $25.833,04$ & $20.966,04$ \\
Beterraba & 1,00 & $3.493,33$ & $11.131,87$ & $7.638,54$ \\
\hline
\end{tabular}

$128 \%$ a mais de área para que as culturas no cultivo solteiro produzam o equivalente à produção do consórcio em um hectare (TAB. 5). Estes resultados são concordantes com resultados de outros estudos de consórcios, reportado por Oliveira et al. (2005) e Rezende et al. (2005).

Nos consórcios entre beterraba e rúcula, Cecílio Filho et al. (2003) e Grangeiro et al. (2007) obtiveram maiores índices de uso eficiente da terra, quando as semeaduras da rúcula foram realizadas na mesma época e aos sete dias após a beterraba.

O maior custo operacional foi observado no consórcio estabelecido aos 14 dias após a semeadura da beterraba (TAB. 5). Esse foi respectivamente 39,3 $\%$ superior ao custo obtido com a beterraba em cultivo solteiro. Em relação aos demais consórcios a diferença foi pequena e, deveram-se, principalmente às capinas extras que foram realizadas no referido consórcio.

Apesar do custo operacional do cultivo consorciado ter sido maior que o do cultivo solteiro da beterraba, o aumento significativo na produção por área no consórcio refletiu-se positivamente sobre a receita bruta, resultando, assim, em maior receita líquida (TAB. 5), corroborando com os trabalhos de Cecílio Filho e May (2002) e Rezende et al. (2004) ao confirmarem ter obtido melhores retornos econômicos no consórcio comparativamente ao cultivo solteiro, sobretudo pela maior receita bruta gerada neste sistema.

\section{Conclusão}

O cultivo consorciado de beterraba com coentro é agroeconomicamente viável. Ele deve ser estabelecido com o plantio do coentro realizado simultaneamente ou aos sete dias após a semeadura da beterraba.

\section{Referências}

BEZERRA NETO, F. et al. Desempenho agroeconômico do consórcio cenoura $\mathrm{x}$ alface lisa em dois sistemas de cultivo. Horticultura Brasileira, v. 21, n. 04, p. 635-641, 2003.
BEZERRA NETO, F. et al. Associação de densidades populacionais de cenoura e alface no desempenho agronômico da cenoura em cultivo consorciado em faixa. Horticultura Brasileira, v. 23, n. 02, p. 233-237, 2005.

CARMO FILHO, F. do; ESPÌNOLA SOBRINHO, J.; MAIA NETO, J. M. Dados climatológicos de Mossoró: um município semi-árido nordestino. Mossoró: ESAM, 1991. 121 p.

CATELAN, F.; NARDIN, R. R.; CECILIO FILHO, A. B. Efeito do consórcio de beterraba e rúcula sobre sua produtividade. In: CONGRESSO BRASILEIRO DE OLERICULTURA, 41, 2001, Brasília. Anais... Brasília: ABH, 2001. 1 CD-ROM.

CAVALCANTI, J. A. Recomendações de adubação para o estado de Pernambuco ( $2^{\circ}$ aproximação). 2. ed. Recife: IPA, 1998, 198 p.

CECILIO FILHO, A. B.; MAY, A. Produtividade das culturas de alface e rabanete em função da época de estabelecimento do consorcio, em relação aos monocultivos. Horticultura Brasileira, v. 20, n. 03, p. 501-504, 2002.

CECÍLIO FILHO, A. B.; TAVEIRA, M. C. G.; GRANGEIRO, L. C. Productivity of beet and roqutte cultivation as a function of time of establishing intercropping. Acta Horticuturae, n. 607, p. 91-95, 2003.

CERETTA, C. A. Sistemas de cultivo de mandioca em fileiras simples e duplas em monocultivo e consorciada com girassol. 1986. 126 f. Dissertação (Mestrado em Agronomia) Universidade Federal do Rio Grande do Sul, Porto Alegre.

COSTA, C.C. et al. Viabilidade agronômica do consórcio de alface e rúcula, em duas épocas de cultivo. Horticultura Brasileira, v. 25, n. 01, p. 34-40, 2007.

FREITAS, K. K. C. et al. Uso de efluente e água de rio no desempenho agroeconômico de cenoura, alface e coentro em associação. Revista Caatinga, v. 17, n. 02, p. 98-104, 2004.

GRANGEIRO, L. C. et al. Produtividade da beterraba e rúcula em função da época de plantio em monocultivo e consórcio. Horticultura Brasileira, v. 25, n. 04, p. 577-581, 2007.

GLIESSMAN, S. R. Agroecologia: processos ecológicos em agricultura sustentável. 2. ed. Porto Alegre: Ed. da Universidade, 2001. $653 \mathrm{p}$.

HUMPHRIES, A. W. et al. Over-cropping lucerne with wheat: effect of lucerne winter activity on total plant production and water use of the mixture, and wheat yield and 
quality. Australian Journal of Agricultural Research, v. 55, n. 08, p. 839-848, 2004.

NEGREIROS, M. Z. et al. Cultivares de alface em sistemas solteiro e consorciado com cenoura em Mossoró. Horticultura Brasileira, v. 20, n. 02, p. 162-166, 2002.

OLIVEIRA, E. Q. et al. Desempenho agroeconômico do bicultivo de alface em sistema solteiro e consorciado com cenoura. Horticultura Brasileira, v. 22, n. 04, p. 712-717, 2004.

OLIVEIRA, E. Q. et al. Produção e valor agroeconômico no consórcio entre cultivares de coentro e de alface. Horticultura Brasileira, v. 23, n. 02, p. 285-289, 2005.

PIMENTEL, M. S.; LANA, A. M. Q.; DE-POLLI, H. Rendimentos agronômicos em consórcio de alface e cenoura adubadas com doses crescentes de composto orgânico. Revista Ciência Agronômica, v. 40, n. 01, p. 106-112, 2009.

RIBEIRO JÚNIOR, J. I. (Ed.). Análises estatísticas no SAEG. Viçosa: UFV, 2001. 301 p.

REZENDE, B. L. A. Análise de produtividade e rentabilidade das culturas de pimentão, repolho, rúcula, alface e rabanete em cultivo consorciado. 2004. $60 \mathrm{f}$. Dissertação (Mestrado em Agronomia) - Faculdade de Ciências Agrárias e Veterinárias, Universidade Estadual Paulista, Jaboticabal.

REZENDE, B. L. A. et al. Análise econômica de cultivos consorciados de alface americana $\mathrm{x}$ rabanete: um estudo de caso. Horticultura Brasileira. v. 23, n. 03, p. 853-858, 2005.
SALVADOR, D. J. et al. Produção e renda bruta de cebolinha e de Almeirão, em cultivo solteiro e consorciado. Acta Scientiarum Agronomy, v. 26, n. 04, p. 491- 496, 2004.

SANTANA, C. V. S. et al. Desempenho de cultivares de alface americana em ambientes sombreados na região do submédio São Francisco-BA. Revista Caatinga, v. 22, n. 04, p. 60-64, 2009.

SOUZA, B. S. et al. Acúmulo e exportação de nutrientes em beterraba. In: CONGRESSO BRASILEIRO DE OLERICULTURA，46，2006，Goiânia. Anais... Goiânia: ABH, 2006. 1 CD-ROM.

SOUZA, J. P.; MACEDO, M. A. S. Análise de viabilidade agroeconômica de sistemas orgânicos de produção consorciada. ABCustos Associação Brasileira de Custos, v. 02, n. 01, p. 57-78, 2007.

TEÓFILO, T. M. S. Crescimento de cultivares de cenoura nas condições de Mossoró-RN. Revista Caatinga, v. 22, n. 01, p. 168-174, 2009

TOLENTINO JÚNIOR, C. F. et al. Produção da mandioquinhasalsa consorciada com alface e beterraba. Acta Scientiarum Agronomy, v. 24, n. 05, p. 1447-1454, 2002.

WILLEY, R. W. Intercropping - Its importance and research needs. Part. 1 - Competition and advantages. Field Crop Abstracts, v. 32, n. 01, p. 1-10, 1979.

VIERA, M. C. et al. Produção e renda de mandioquinha salsa e alface, solteira e consorciados, com adubação nitrogenada e cama de frango em cobertura. Acta Scientiarum Agronomy, v. 25, n. 01, p. 201-208, 2003. 